\title{
Run-up on Vertical Piles due to Regular Waves: Small-scale Model Tests and Prediction Formulae
}

\author{
Lisham Bonakdar $^{1 *}$, Hocine Oumeraci ${ }^{1}$ and Amir Etemad-Shahidi ${ }^{2}$ \\ ${ }^{1}$ Leichtweiss-Institute for Hydraulic Engineering and Water Resources, Technische Universität \\ Braunschweig, Beethovenstrasse. 51a, 38106 Braunschweig, Germany \\ ${ }^{2}$ Griffith School of Engineering, Griffith University Gold Coast Campus, QLD 4222, Australia \\ * Corresponding Author, Phone: +495313913938, E-mail: 1.bonakdar@tu-braunschweig.de
}

\begin{abstract}
In wave-structure interaction, one of the most important phenomena clearly identified is wave runup on offshore structures. In this study, wave run-up on a slender pile due to non-breaking regular waves is investigated by means of small-scale experiments performed in the $2 \mathrm{~m}$-wide wave flume of Leichtweiss-Institute for Hydraulic Engineering and Water Resources (LWI) in Braunschweig, Germany. The test programme is designed to generate a comprehensive data set covering a broader range of wave conditions including not only deep and intermediate water conditions but also nearly shallow and shallow water conditions, which are missing in the available laboratory studies on wave run-up on piles. The relative wave height $(H / h)$, relative water depth $(h / L)$ and slenderness of pile $(D / L)$ are identified as the key parameters governing the relative wave run-up $\left(R_{u} / H\right)$. Based on these parameters, new formulae covering the range of tested conditions $(0.028 \leq H / h \leq 0.593$, $0.042 \leq h / L \leq 0.861,0.003 \leq D / L \leq 0.206$ ) are developed to predict regular non-breaking wave run-up on single piles using a combination of the M5 model tree and nonlinear regression techniques. Using statistical accuracy metrics such as agreement index $I_{a}$, squared correlation coefficient $R^{2}$ and scatter index $S I$, the performance of the developed formulae is evaluated. It is shown that the new formulae outperform the current formulae in predicting regular wave run-up on single piles. This success is in part due to the explicit account for the water depth in the new experiments and formulae. The proposed model is valid for a wider range of wave conditions and, therefore, more appealing for engineering practice compared to those available for the estimation of regular wave run-up.
\end{abstract}

\section{Keywords}

Wave run-up; Vertical pile; Regular wave; Water depth condition; M5 model tree; Prediction formulae 


\section{Introduction}

\subsection{Importance of the study}

Europe is the world leader in offshore wind power, with the first offshore wind farm built in Denmark in 1991. The design and construction of support structures for offshore wind turbines is one of the most challenging issues in civil engineering. One of the important issues in the design of offshore support structures (e.g. oil and gas platforms, offshore wind turbines and piers) is wave run-up. Wave run-up is referred to the vertical upward rush of water that occurs when an incident wave hits a partially immersed structure. It is an important parameter for the assessment of wave loads on surface-piercing offshore structures. Wave run-up height also plays an important role in designing the free board of offshore support structures.

A failure of an offshore structure would not only cause significant financial losses, but might also result in widespread environmental damages underlining the importance of the safe design of support structures. For example, the underestimation of wave run-up on a wind turbine's support structure in the Horns Reef 1 wind turbine park in Denmark led to damage to the structure (Lykke Andersen et al., 2011).

\subsection{State of the art}

Considerable studies have been dedicated to wave run-up on vertical piles, including a large number of analytical, experimental and numerical studies. Among the investigations on wave runup on vertical piles, McCamy and Fuchs (1954) was one of the first researchers to study wave field around a vertical pile based on linear diffraction theory. The following formula was proposed for the calculation of surface elevation around vertical circular piles.

$$
\eta(\theta)=\frac{H}{2} \sqrt{1+(2 k a \cdot \cos \theta)^{2}} \sin (\omega t-\psi)
$$

where $\eta$ is the surface elevation, $\theta$ is the angle measured from the front centre of the pile, $H$ is the wave height, $k$ is the wave number, $a$ is the radius of the vertical pile, $\omega$ is the angular frequency, $t$ is time and $\psi$ is defined as follow:

$\psi=\tan ^{-1}(2 k a \cos \theta)$

For the estimation of wave run-up $R_{u}$ on the front side of a vertical pile, the following formula was proposed: 
$\frac{R_{u}}{\eta_{\max }}=\left(1+(2 k a)^{2}\right)^{-0.5}$

The linear diffraction theory is valid only for small wave heights. This theory was also applied by Sarpkaya and Isaacson (1981) for the estimation of the wave surface elevation around vertical piles. Using different methods, diffraction theory was extended to the second order in some studies (e.g. Kim and Hue, 1989; Kriebel, 1990; Martin et al., 2001).

Based on the so-called velocity stagnation head theory, Hallermeier (1976) proposed a formula for the prediction of wave run-up on vertical piles. The idea behind the velocity stagnation head concept is that when a wave hits a structure, the kinetic energy of the water particles at the wave crest has to be converted into potential energy by rising a distance equal to $u^{2} / 2 g$ up the pile above the crest elevation. Based on this approach, the following formula was proposed for the prediction of wave run-up $R_{u}$ on vertical piles:

$$
R_{u}=\eta_{\max }+m \frac{u^{2}}{2 g}
$$

where $\eta_{\max }$ is the maximum wave crest elevation, $m$ is an adjustment coefficient, $u$ is the water particle velocity at $\eta_{\max }$ and $g$ is the gravity acceleration. For long waves, in which wave kinematics are calculated using solitary wave theory, Hallermeier (1976) proposed $m$ coefficient to be equal to 1 .

Niedzwecki and Duggal (1992) studied wave run-up on vertical piles due to regular and irregular waves by means of small-scale laboratory tests. Wave run-up values were measured using spaced resistance type wave gauges which were placed directly on the surface of the tested pile with a diameter of $D=0.114 \mathrm{~m}$. Based on the linear wave theory, the maximum wave-induced flow velocity was calculated at the still water level (SWL) which resulted in $m=6.83$ and $\eta_{\max }=H / 2$. Niedzwecki and Huston (1992) proposed $m=6.52$ and $\eta_{\max }=0.56 H$ to alter the linear fit and proposed the following formula:

$$
R_{u}=0.56 H+6.52 \frac{u^{2}}{2 g}
$$

Martin et al. (2001) also investigated regular wave run-up on a vertical pile $(D=0.11 \mathrm{~m})$ by means of small-scale laboratory tests. They compared the results of the laboratory tests with different approaches. They found poor agreements between the results of the laboratory tests and those obtained from both linear diffraction theory and velocity stagnation head method. By means of 
small-scale laboratory tests, Mase et al. (2001) studied wave run-up of random waves on a circular pier installed on a uniform slope bottom; under various wave conditions and bottom slopes. They also derived a prediction formula for the run-up height $R_{u 2} \%$.

De Vos et al. (2007) experimentally investigated wave run-up on vertical piles exposed to regular and irregular waves. Their tests covered only intermediate and deep water conditions. Wave runup heights were measured using (i) the resistance-type wave gauges mounted around the pile ( $D=0.12 \mathrm{~m}$ ) with approximately $2 \mathrm{~mm}$ from the pile surface and (ii) video recording. They found out that due to the $2 \mathrm{~mm}$ distance between the wave gauges and pile surface, wave run-up is slightly underestimated for thin run-up layers, which are caused by the highest waves with very high runup levels. As they stated, however, the video recording provided accurate measuring of wave runup on piles. Lykke Andersen and Frigaard (2006) studied wave run-up on vertical piles due to regular and irregular waves by conducting small-scale laboratory tests. The wave run-up levels were measured using resistance-type wave gauges placed around the pile with approximately 2 $\mathrm{mm}$ from the pile surface. Their laboratory experiments were limited to intermediate water depth $(0.85 \leq h / L \leq 0.14)$.

De Vos et al. (2007) used the velocity stagnation head theory (Eq. 4) for the prediction of wave run-up on piles. For the case of regular waves, they reported that $m=1$ results in the underestimation of wave run-up when the horizontal wave-induced flow velocity is calculated based on the linear wave theory. They also found out that the formula proposed by Niedzwecki and Duggal (1992) overestimates the wave run-up on a single pile. De Vos et al. (2007), however, concluded that $m=1$ provides a reasonable estimation of regular wave run-up on vertical piles when the second order of Stokes theory is applied for the computation of horizontal flow velocity. Lykke Andersen et al. (2011) re-analysed the laboratory data of De Vos et al. (2007) and found out that stream function theory provides less scatter in predicting the adjustment coefficient, $m$ compared to the second order of Stokes theory. They also stated that by increasing wave height to water depth ratio or relative wave height $H / h$, the adjustment coefficient $m$ increases; i.e. wave nonlinearity affects wave run-up. Motivated by this implication, Peng et al (2012) investigated numerically wave runup on single piles. They found out that wave non-linearity significantly affects wave run-up heights. They showed, in fact, that wave run-up depends on Ursell number $U r=H L^{2} / h^{3}$, which includes both $H / h$ and $h / L$ parameters. They also stated that wave run-up increases as the pile diameter $D$ increases. They stated that their numerical model might not be valid for Ursell number larger than 70. According to the tested wave conditions and water depth, their study is limited to intermediate water depth and does not cover shallow water condition. 
Ramirez et al. (2013) studied wave run-up of irregular waves on vertical piles by conducting large scale experiments in the large wave flume (GWK) of the Forschungzentrum Küste (FZK) in Hannover, Germany. The focus of their study was on the near breaking and breaking waves. The wave run-up events on the tested pile with a diameter of $0.56 \mathrm{~m}$ were recorded by a high speed video camera as they found out that the wave gauges placed around the pile underestimate wave run-up heights. They classified wave run-up heights in three levels, including green water layer (level A), thin layer of mixed water and air (level B) and maximum spray (level C).

Recently, Kazeminezhad and Etemad-Shahidi (2015) investigated regular and irregular wave runup on vertical piles using the laboratory data sets of Andersen and Frigaard (2006), De Vos et al. (2007) and Ramirez et al. (2013). In contrast to the most of previous studies, in which wave runup on vertical piles was estimated based on the velocity stagnation head theory, Kazeminezhad and Etemad-Shahidi (2015) estimated wave run-up height for non-breaking waves based on the non-dimensional wave parameters. They determined the ratio of wave height to water depth $H / h$ and the ratio of the local wave height to deep water wave length $H / L_{0}$ as the governing parameters for the estimation of the relative wave run-up height $R_{u} / H$. Based on these two non-dimensional parameters and using a combination of the M5 model tree (M5MT) and nonlinear regression techniques, they proposed the following formulae for the prediction of regular wave run-up on vertical piles:

$$
\begin{aligned}
& \frac{R_{u}}{H}=0.76\left(\frac{H}{h}\right)^{0.15}\left(\frac{H}{L_{0}}\right)^{-0.055} \quad \frac{H}{h} \leq 0.41 \\
& \frac{R_{u}}{H}=0.65\left(\frac{H}{L_{0}}\right)^{-0.055}+3.2 \times 10^{-3}\left(\frac{H}{h}-0.41\right)^{0.15}\left(\frac{H}{L_{0}}\right)^{-1.5} \quad \frac{H}{h}>0.41
\end{aligned}
$$

Their formulae are more practical as the wave run-up $R_{u}$ can be estimated directly from wave parameters $\left(H\right.$ and $\left.L_{0}\right)$ and water depth $h$. However, the proposed formulae (Eqs. 6 and 7) do not cover nearly shallow and shallow water conditions. Some of the abovementioned studies proposed formulae for the estimation of irregular wave run-up on single piles, which are summarized in Table 1 and are not further discussed in this paper.

\subsection{Motivation of this study}

The abovementioned studies have contributed to enhance the knowledge on the estimation of regular wave run-up on single piles. However, the conducted laboratory tests were mostly focused on vertical piles in intermediate and deep water conditions and there is a lack of information in shallow water conditions. As a result, the proposed empirical formulae have some limitations. The 
empirical formulae, which are developed based on the velocity stagnation head theory, the wave kinematics should be necessarily calculated using an appropriate wave theory and the adjustment coefficient $m$ is directly affected by the used wave theory. The formulae proposed by Kazeminezhad and Etemad-Shahidi (2015) are independent of any wave theory (for the determination of wave kinematics). However, their proposed formulae are based on the data sets which are limited to deep and intermediate water conditions; while a formula for shallow water conditions, where relatively larger wave run-up heights can be expected, is not available. These limitations underline the necessity of further investigations of wave run-up on single piles considering not only deep and intermediate water depths, where some types of offshore oil platforms and wind turbines (e.g. jacket-type support structures) are located, but also shallow and nearly shallow conditions, where monopile-type sub-structures for offshore wind turbines and piers might be constructed.

In this study, wave run-up on a slender pile due to non-breaking regular waves is investigated by means of small-scale experiments. The performed tests cover a broad range of hydrodynamic conditions, which allow us to identify the most relevant non-dimensional hydrodynamic parameters affecting the wave run-up on a single pile. Based on the identification of the most significant non-dimensional hydrodynamic parameters, new formulae for the estimation of regular wave run-up on single piles are developed using a combination of M5 model tree (M5MT) and nonlinear regression techniques. The new formulae are developed, based on a wider range of parameters and therefore applicable for a wider range of wave conditions and different water depths including shallow, intermediate and deep.

This paper is outlined as follows: The LWI laboratory tests including the model set-up, deployed measuring techniques and wave conditions are described in Section 2. Using the LWI laboratory tests, the performance of the recently developed formulae for the prediction of regular wave runup is then evaluated in Section 3. Next, the M5 model tree (M5MT) approach is briefly introduced. In Section 5, the developed new formulae for the prediction of regular wave run-up of single piles are presented, and the obtained results are discussed. Finally, the key results are summarized and concluding remarks are drawn in Section 6.

\section{LWI laboratory tests}

The experimentally investigation of wave run-up on vertical single piles is a part of a research project supported by the German Research Foundation (DFG) and entitled "Breaking and NonBreaking Wave Load on Pile Group-Supported Marine Structures" (WaPiGS) at Leichtweiß- 
institute (LWI), Technische Universität Braunschweig. The main objective of this research project is to improve the understanding of the processes associated with the interaction of waves and pile groups. Within this project, a large number of laboratory tests including single pile and pile groups with different arrangements were carried out in the 2-m wide wave flume of LWI. The twin wave flume of LWI, which is shown in Fig. 1, consists of 2-m and 1-m wide flumes that are $90 \mathrm{~m}$ long and $1.25 \mathrm{~m}$ deep. The position of the tested pile is also shown in Fig 1. The plan view and cross section of the model set-up for the case of a single pile are drawn in Figs. 2 and 3, respectively. As seen in Fig. 3, the constructed 1-m long pile with a diameter of $D=0.05 \mathrm{~m}$ was supported from the top and stretched to the bottom of the wave flume with a gap of only a $2-\mathrm{cm}$ between piles and bottom. As pile dimeter was noticeably smaller than the $2 \mathrm{~m}$ wide wave flume of the LWI, there was no blockage effect from the flume's wall on the measurements.

Two high-speed video cameras capable of recording up to 60 images (frames) per second were used for measuring wave run-up levels of individual waves. In addition to the high-speed video cameras, videos were made to determine the instances of the highest run-up events. In order to determine wave run-up levels on the pile from the high-speed video images as accurate as possible, marks were placed every $2 \mathrm{~cm}$ on the pile. For each test, the wave run-up heights were measured for events in a regular wave train including only incident waves ( $N=5$ to 15 waves depending on the wave period) without any interaction from the waves reflected from the end of wave flume. The wave run-up value used for data analysis is, in fact, the average of these measured wave run-up events in a regular wave train. Based on the wave period, the number of run-up events considered for averaging was different from 5 to 15 for different tests. The average and relative standard deviation (RSD) of the measured wave run-up events in a regular wave train are given in Table 2. Fig. 4 shows an example of a run-up event on the tested single pile due to a regular wave with wave height of $0.29 \mathrm{~m}$ and wave period of $3.5 \mathrm{sec}$.

Wave height and period were also measured using deployed wave gauges. In addition to the wave run-up, local and total wave-induced forces as well as the moment on the pile were measured using the transducers and shown in Fig. 3. An Acoustic Doppler Velocimeter (ADV) was used to measure the undisturbed horizontal wave-induced flow velocity at three different relative elevations of the water column $(z / h=0.78,0.53$ and 0.28$)$ exactly where the so-called ring transducers were placed for measuring the local wave-induced force. More information regarding the model set-up and measuring devices can be found in Bonakdar (2014) and Bonakdar and Oumeraci (2015). Regular non-breaking waves with 22 different combinations of wave heights and periods were tested to cover a broad range of hydrodynamic conditions (Table 2). Relative wave height $H / h$ varied from 0.07 to 0.517 . Wave steepness varied from 0.008 to 0.073 , which was the maximum possible wave steepness without incipient breaking. Relative water depth $h / L$ 
varies from 0.042 to 0.64 meaning that deep, transition and shallow water conditions were considered (Table 3).

\section{Evaluation of available formulae for the prediction of regular wave run-up}

Before developing a new formula for the estimation of the wave run-up on single piles due to regular waves, the performance of the available formulae for the prediction of regular wave runup on piles was evaluated using the LWI laboratory data. Among the available studies mentioned in Section 1.2, De Vos et al. (2007) and Kazeminezhad and Etemad-Shahidi (2015) proposed formulae for regular wave run-up on vertical piles. Based on the velocity stagnation head theory (Eq. 4), De Vos et al. (2007) proposed the adjustment coefficient $m$ to be equal to 1 when the horizontal wave-induced flow velocity is calculated based on the second order of Stokes theory. As shown by Kazeminezhad and Etemad-Shahidi (2015), the data, based on which the formula of De Vos et al. (2007) was developed, are in the range of the second, third and fifth orders of Stokes as well as Stream Function theories. However, as recommended by De Vos et al. (2007), the maximum wave crest elevation, $\eta_{\max }$, and the water particle velocity $u$ at $\eta_{\max }$ were calculated based on second order Stokes theory and $m$ coefficient was set to 1 . The comparison between wave runup levels measured in the LWI wave flume and those calculated by De Vos et al. (2007) formula is depicted in Fig. 5. The performance of their formula was quantitatively evaluated using statistical indicators such as agreement index $I_{a}$, squared Pearson correlation coefficient $R^{2}$, scatter index SI, and Bias respectively defined as follow:

$I_{a}=1-\frac{\sum_{i=1}^{n}\left(x_{i}-y_{i}\right)^{2}}{\sum\left(\left|x_{i}-\bar{x}\right|+\left|y_{i}-\bar{y}\right|\right)^{2}}$

$R^{2}=\frac{\left(\sum_{i=1}^{n}\left(x_{i}-\bar{x}\right)\left(y_{i}-\bar{y}\right)\right)^{2}}{\sum_{i=1}^{n}\left(x_{i}-\bar{x}\right)^{2} \sum_{i=1}^{n}\left(y_{i}-\bar{y}\right)^{2}}$

$S I=\frac{\sqrt{1 / n \sum\left(y_{i}-x_{i}\right)^{2}}}{\bar{x}}$

Bias $=\bar{y}-\bar{x}$ 
where $x_{i}$ and $y_{i}$ denote the predicted and the measured values, respectively and $n$ is the number of measurements (data). $\bar{x}$ and $\bar{y}$ are the corresponding mean values of the predicted and measured parameters. In general, a large scatter is seen in Fig. 5. The main reason of this large scatter is due to the fact that the suggested second order Stokes wave theory for the calculation of wave kinematics is not valid for waves with a higher degree of non-linearity, especially where stream function theory need to be considered. The scatter of the data points is only seen in waves for which the stream function theory is appropriate. The performance of the De Vos et al. (2007) formula in predicting regular wave run-up was individually evaluated using the tests for which the second order Stokes can be applied (Fig. 6). As seen, for these tests, the proposed formula is able to estimate wave run-up levels precisely. It can, therefore, be concluded that the formula proposed by De Vos et al. (2007) can be used when the suggested second order Stokes is appropriate for the calculation of wave kinematics.

The performance of the Kazeminezhad and Etemad-Shahidi (2015) method (Eq. 6 and 7) in predicting regular wave run-ups on vertical piles was also evaluated using the LWI data. Fig. 7 illustrates the comparison between regular wave run-up heights measured in the LWI wave flume and those estimated by their formulae. As demonstrated in Fig. 7, it seems that for the tests with $H / h \leq 0.41$ the proposed formula (Eq. 6) can reasonably predict the wave run-up heights while for the tests with $H / h>0.41$, the proposed formula (Eq. 7) significantly overestimates wave run-up values. The high overestimation of these data points, shown in Fig. 7, affects the accuracy of the formulae as confirmed by the statistical indicators (Fig. 7).

This large scatter between measured and predicted data for the tests with $H / h>0.41$ might be due to the high degree of non-linearity of the waves which might not have been properly considered in Eq. 7. In fact, Kazeminezhad and Etemad-Shahidi (2015) used deep-water wave length $L_{0}$ for the wave height to deep water wave length ratio, $H / L_{0}$. However, for waves with a high degree of nonlinearity, wave length $L$ might be more appropriate. It should also be mentioned that the formulae of Kazeminezhad and Etemad-Shahidi (2015) were developed for the estimation of regular wave run-up on piles based on the laboratory data sets of Andersen and Frigaard (2006) and De Vos et al. (2007). The used data sets, in fact, do not fully cover shallow or nearly shallow water conditions, and the minimum relative water depth $h / L$ is 0.084 ; while the LWI data points with $H / h>0.41$, for which Eq. 7 noticeably overestimates wave run-up, are located in shallow or nearly shallow water conditions, and their $h / L$ values vary from 0.042 to 0.074 .

In order to get a better understanding of the proposed formula for the cases with $H / h \leq 0.41$ (Eq. 6), the result of the comparison of the measured and predicted wave run-up values is separately shown in Fig. 8. The values of the four statistical indicators are also shown in Fig. 8. As seen, the proposed 
formula can accurately predict wave run-up levels for $H / h \leq 0.41$. For this condition, agreement index $I_{a}$ is 0.985 and scatter index $S I$ is $12.9 \%$. It can, therefore, be concluded that the formulae proposed by De Vos et al. (2007) and Kazeminezhad and Etemad-Shahidi (2015) can predict regular wave run-up heights accurately only within the conditions they are valid for. In other words, De Vos et al. (2007) formula may not be applied for waves with a higher degree of nonlinearity, especially where stream function theory need to be considered for the calculation of wave kinematics; and Kazeminezhad and Etemad-Shahidi (2015) formulae may not be applicable in shallow or nearly shallow water conditions.

These limitations underline the necessity of developing new formulae for a more accurate estimation of regular wave run-up on single piles. In order to prevent pre-calculations for the determination of wave kinematics, which is one of the main disadvantages of the formulae based on velocity stagnation head theory, the approach of Kazeminezhad and Etemad-Shahidi (2015) was adopted for this study. This means that the relative wave run-up was estimated as a function of the most relevant non-dimensional wave parameters using M5 model tree method introduced in the next section.

\section{M5 model tree (M5MT)}

The M5 model tree was introduced by Quinlan (1992) and represents one of the most recent computational tools for data analysis, which can be applied for prediction purposes. M5MT has a unique algorithm and for a given data set of input and output variables, the model provides a unique solution for any number of simulations. Recently, M5MT has been successfully employed for water level discharge relationship (Bhattacharya and Solomatine, 2005), sediment transport (Bhattacharya et al., 2007), stability of rubble-mound breakwaters (Etemad-Shahidi and Bonakdar, 2009; Etemad-Shahidi and Bali, 2012), prediction of wave run-up on rubble-mound breakwaters (Bonakdar and Etemad-Shahidi, 2011), estimation of longitudinal dispersion (Etemad-Shahidi and Taghipour, 2012), prediction of scour depth under submarine pipeline (Etemad-Shahidi et al., 2011), wave overtopping at rubble-mound structures (Jafari and Etemad-Shahidi, 2012), estimation of scour depth around circular piers (Etemad-Shahidi et al., 2015), wave induced-force on pile groups (Bonakdar et al., 2015) and estimation of wave run-up on single piles (Kazeminezhad and Etemad-Shahidi, 2015).

The concept of the model tree approach is based on dividing complex problems into smaller subproblems and solving each sub-problem (Bhattacharya et al., 2007). The concept of M5MT is described in Fig. 9 by a simple example with two input parameters $\left(X_{1}\right.$ and $\left.X_{2}\right)$. As shown in Fig. 
9A, M5MT is similar to an inverse tree with a root node at the top and a number of leaves at the bottom. Firstly, the M5MT algorithm constructs a tree by splitting the instance space (data points). Fig 9A shows the constructed tree while Fig 9B illustrates the classified data. The splitting condition is used to minimize the intra-subset variability in the values down from the root through the branch to the node. The variability is measured by the standard deviation of the values that reach that node from the root through the branch, the expected reduction in error being calculated as a result of testing each attribute at that node. In this way, the attribute (input parameter) that maximizes the expected error reduction is chosen. The splitting process is performed only if either the output values of all the instances that reach the node, called leaf, vary slightly or a few instances remain. The standard deviation reduction $(S D R)$ is calculated as (Quinlan 1992):

$$
S D R=s d(T)-\sum_{i} \frac{\left|T_{i}\right|}{|T|} \times s d\left(T_{i}\right)
$$

where $T$ is the set of examples that reach the node, $T_{i}$ are the sets that result from splitting the node according to the chosen attribute and $s d$ is the standard deviation (Wang and Witten 1997). After the initial tree has been grown, the linear regression models are generated, using the data associated with that leaf. Fig. 9C shows the possible linear regression models for the given example. In the second step, all sub-trees are considered for pruning. Pruning occurs if the estimated error for the linear model at the root of a sub-tree is smaller or equal to the expected error for the sub-tree. In this way, the sub-trees which cannot improve the accuracy of the model are pruned. After pruning, there is a possibility that the pruned tree might have discontinuities between nearby leaves. If required, to compensate discontinuities among adjacent linear models in the leaves of the tree a regularization process is performed, which is called smoothing process. Details of the pruning and smoothing processes can be found in Wang and Witten (1997). As stated by Kazeminezhad and Etemad-Shahidi (2015), M5MT provides a linear relationship between input and output parameters

at each leaf, while the relationships between the output and input parameters are not necessarily linear. Therefore, in this study after classifying homogenous data points using M5MT, nonlinear regression technique was used to develop prediction formulae. In order to develop new formulae for the estimation of regular wave run-up on single piles, the most relevant influencing parameter should firstly be determined.

\section{New wave run-up formulae}

In order to develop generic formulae for the estimation of wave run-up on vertical piles due to regular waves, the LWI tests, in addition to those of Lykke Andersen and Frigaard (2006) and De 
Vos et al. (2007) were used. In this way, a more comprehensive data set covering a wider range of wave and pile conditions was achieved which may consequently result in more generic prediction formulae. Table 4 provides an overview of the hydrodynamic conditions of the abovementioned data sets used for the development of the run-up formulae.

Wave run-up on vertical piles might be influenced by both pile and wave characteristics. This might specifically include pile diameter $D$, wave height $H$, wave period $T$, wave length $L$ as well as water depth $h$. The bed characteristics might also affect the wave parameters. As the flat bottom is only considered in this study, bed condition is not concerned. Therefore, it can be stated that:

$$
R_{u}=f\{D, h, H \text { and } L(\text { or } T)\}
$$

In order to develop generic formulae, dimensional parameters measured in the small-scale laboratory tests cannot be directly used. Hence, non-dimensional parameters influencing wave runup height need to be determined. For this purpose, sensitivity analysis was performed to determine the most significant non-dimensional parameters out of the possible non-dimensional parameters (e.g. wave steepness $H / L$, relative wave height $H / h$, relative water depth $h / L$, scattering or slenderness parameter $D / L$ and the Ursell number, $U r=H L^{2} / h^{3}$, which may represent the ratio of $H / L$ to $(h / L)^{3}$ or the ratio of $H / h$ to $\left.(h / L)^{2}\right)$. Finally, it was found that the relative wave run-up on the pile $R_{u} / H$ can be described in the non-dimensional form as follows:

$$
\frac{R_{u}}{H}=f\left\{\frac{H}{h}, \frac{h}{L}, \frac{D}{L}\right\}
$$

The squared Pearson correlation coefficient $R^{2}$ between the abovementioned non-dimensional influencing parameters and the relative wave run-up are given in Table 5. To apply M5MT for the analysis of the data, relative wave run-up $R_{u} / H$ was set as the output of the model and the relative wave height $H / h$, relative water depth $h / L$, and scattering or slenderness parameter $D / L$ were set as the input parameters. In total, 92 tests with regular waves including $22 \mathrm{LWI}$ data, 22 data from Andersen and Frigaard (2006) and 48 data from De Vos et al. (2007) were used. M5MT was applied for classifying the data and as a result the data set was classified into two subclasses based on the relative wave height parameter $H / h$, which is also known as the splitting parameter with the corresponding splitting value of 0.41 .

The result of the data classification is completely in agreement with that presented by Kazeminezhad and Etemad-Shahidi (2015). In fact, their model classified their dataset into two classes based on the relative wave height $H / h$ with the corresponding splitting value of 0.41 . This agreement is obtained despite the fact that (i) their dataset did not include LWI data and (ii) the 
input parameters of their M5MT model including $H / h$ and $H / L_{0}$ are not the same as those used in this study, i.e. $H / h, h / L$ and $D / L$. This might be due to the high correlation between $R u / H$ and $H / h$ in both models compared to the correlation between other input parameters and $R u / H$ as shown in Table 5 .

After the classification process, formulae were developed using nonlinear regression techniques for each subclass. Finally, the simplest and most accurate formulae obtained for the prediction of wave run-up on vertical piles due to regular waves were proposed as follows:

$$
\begin{aligned}
& \frac{R_{u}}{H}=0.863\left(\frac{H}{h}\right)^{0.117}\left(\frac{h}{L}\right)^{-0.206}\left(\frac{D}{L}\right)^{0.108} \quad \frac{H}{h} \leq 0.41 \\
& \frac{R_{u}}{H}=0.777\left(\frac{h}{L}\right)^{-0.206}\left(\frac{D}{L}\right)^{0.108}+0.138\left(\frac{H}{h}-0.41\right)^{0.316}\left(\frac{h}{L}\right)^{-2.6}\left(\frac{D}{L}\right)^{1.16} \quad \frac{H}{h}>0.41
\end{aligned}
$$

In the new formulae (Eq. 15a and 15b), wave dispersion is considered by $h / L$, wave nonlinearity by $H / h$ and wave diffraction regime by $D / L$. It can also be concluded from these formulae that relative wave run-up, $R u / H$ increases as $H / h$ increases which is in agreement with the results of previous studies. Besides, relative water depth $h / L$ affects the run-up level and wave run-up increases when $h / L$ decreases. These indicate that wave run-up on pile increases with increasing non-linearity and decreasing dispersion of the incident wave, which (for non-linear waves) both depend on the wave characteristics $H$ and $L$ as well as on water depth $h$. The new formulae also show that the relative wave run-up increases by increasing wave diffraction represented by the pile slenderness parameter $D / L$. The latter was not determined as a significant parameter affecting wave run-up heights by Kazeminezhad and Etemad-Shahidi (2015). This might be due to the limited range of slenderness parameter considered $(0.02 \leq D / L \leq 0.07)$ as compared to those used in this study $(0.003 \leq D / L \leq 0.07)$.

The performance of the new formulae was quantitatively evaluated using the abovementioned statistical indicators. Fig. 10 illustrates the comparison between measurements in the LWI wave flume and those estimated by the new proposed formulae. As seen, the scatter between measured and predicted $R_{u}$ values is negligibly small. The statistical parameters also indicate that the new formulae can accurately predict regular wave run-up on vertical piles. The scatter diagram of all measured and predicted wave run-ups as well as the statistical values are shown in Fig. 11. As seen, the data points are densely concentrated on the 45-degree line, which represents the ideal correlation. The statistical indicators of $I_{a}=0.983$ and $S I=16.5 \%$ demonstrate the skilfulness of the proposed formulae to reproduce the experimental data. 
For design or a safety assessment, it is recommended to consider the uncertainty of the prediction. Therefore, the proposed formulae were modified for design purposes by considering a factor of safety of one standard deviation $(\sigma)$. For Eq. 15a and 15b, the standard deviation $(\sigma)$ derived from the comparison of measurements and predictions is equal to 0.15 and 0.17 , respectively. As the result, the modified formulae can be proposed as follows:

$$
\begin{aligned}
& \frac{R_{u}}{H}=0.863(1+0.15)\left(\frac{H}{h}\right)^{0.117}\left(\frac{h}{L}\right)^{-0.206}\left(\frac{D}{L}\right)^{0.108} \quad \frac{H}{h} \leq 0.41 \\
& \frac{R_{u}}{H}=(1+0.17)\left(0.777\left(\frac{h}{L}\right)^{-0.206}\left(\frac{D}{L}\right)^{0.108}+0.138\left(\frac{H}{h}-0.41\right)^{0.316}\left(\frac{h}{L}\right)^{-2.6}\left(\frac{D}{L}\right)^{1.16}\right) \quad \frac{H}{h}>0.41
\end{aligned}
$$

In addition, Eq. 16a and 16b were further modified to consider different levels of acceptable risk as follows:

$$
\begin{aligned}
& \frac{R_{u}}{H}=0.863(1+0.15 M)\left(\frac{H}{h}\right)^{0.117}\left(\frac{h}{L}\right)^{-0.206}\left(\frac{D}{L}\right)^{0.108} \quad \frac{H}{h} \leq 0.41 \\
& \frac{R_{u}}{H}=(1+0.17 M)\left(0.777\left(\frac{h}{L}\right)^{-0.206}\left(\frac{D}{L}\right)^{0.108}+0.138\left(\frac{H}{h}-0.41\right)^{0.316}\left(\frac{h}{L}\right)^{-2.6}\left(\frac{D}{L}\right)^{1.16}\right) \quad \frac{H}{h}>0.41
\end{aligned}
$$

where $M$ may be obtained based on desired or acceptable levels of risk (Table 6). As an example, $M$ is equal to 2.05 for a $2 \%$ risk.

\section{Summary, concluding remarks and outlook}

Wave run-up on single piles due to non-breaking regular waves was investigated by means of small scale experiments performed in the LWI wave flume. For this purpose, a test programme was considered covering a broad range of hydrodynamic conditions including deep, intermediate and shallow water conditions. LWI laboratory tests were used for the evaluation of available formulae for estimating regular wave run-up on single piles. It was found that De Vos et al. (2007) formula is limited to the condition in which second order Stokes is appropriate for the calculation of wave kinematics, while Kazeminezhad and Etemad-Shahidi (2015) formulae may not apply for 
the shallow or nearly shallow water conditions. These confirmed that new formulae were required to cover the shallow water condition.

Relative wave height $H / h$, relative water depth $h / L$, and slenderness parameter $D / L$ were determined as the most relevant influencing non-dimensional parameters affecting relative wave run-up $R_{u} / H$. These non-dimensional parameters are physically meaningful as they represent properties of the incident waves such as non-linearity $(H / h)$ and dispersion $(h / L)$ as well as the diffraction regime $(D / L)$. Based on the governing non-dimensional parameters and using LWI tests as well as the datasets from the tests of Lykke Andersen and Frigaard (2006) and De Vos et al. (2007), new formulae were developed for the prediction of regular wave run-up on single piles. The new formulae developed using a combination of the M5 model tree and nonlinear regression techniques, dot not need any pre-calculation of the wave kinematics which requires the selection of the proper wave theory. In fact, wave parameter $H$ and $L$, water depth $h$ and pile diameter $D$ can be directly used to obtain the necessary non-dimensional input parameters. The proposed formulae can accurately estimate regular wave run-up on single piles for a wider range of parameters, and are more appealing for engineering practice compared to other available formulae for the prediction of regular wave run-up on single piles. The performance of the proposed formulae is

confirmed by the values of agreement index $I_{a}$, squared correlation coefficient $R^{2}$ and scatter index SI, which are $0.983,0.94$ and $16.5 \%$, respectively. The developed formulae are valid for nonbreaking waves within the range of hydrodynamic conditions used in this study.

Based on the knowledge gained from this study, the following recommendations for further research may be drawn:

(i) The effect of bottom slope on regular wave run-up height of vertical piles might be investigated. This might particularly be important for shallow water conditions.

(ii) As a large amount of studies and data are available for regular waves, a relationship between run-up induced by random waves and regular waves would provide a guidance on applying run- up formulae and data in engineering practice.

\section{Acknowledgments}

The financial support of the German Research Foundation (DFG, Deutsche Forschungsgemeinschaft) for this study through the WaPiGS project (Ou 1/13-1 and Ou 1/13-2) is acknowledged. The authors are also grateful to Dr. De Vos, Dr. Lykke Andersen and Dr. Frigaard for their valuable laboratory tests on regular wave run-up on single piles as well as to Dr. M. Kazeminezhad for providing the details of his study on wave run-up on vertical piles. 


\section{References}

Bhattacharya, B., Solomatine, D.P., 2005. Neural networks and M5 model trees in modeling water level-discharge relationship. Neurocomputing, 63, 381-396.

Bhattacharya, B., Price, R. K., Solomatine, D. P., 2007. Machine Learning Approach to Modeling Sediment Transport. J. of Hydr. Eng. 133(4), 440-450.

Bonakdar, L., 2014. Pile group effect on the wave loading of a slender pile. $\mathrm{PhD}$ thesis, Technische Universität Braunschweig, Germany (ISBN 978-3-86948-383-2).

Bonakdar, L., Etemad-Shahidi, A., 2011. Predicting wave run-up on rubble-mound structures using M5 model tree, Ocean Engineering, 38, 111-118

Bonakdar, L., Oumeraci, H., 2015. Pile group effect on the wave loading of a slender pile: a smallscale model study. Ocean Engineering, 108, 449-461.

Bonakdar, L., Oumeraci, H., Etemad-Shahidi, A., 2015. Wave load formulae for prediction of wave-induced forces on a slender pile within pile groups. Coastal Engineering, 102, 49-68.

De Vos, L., Frigaard, P., De Rouck, J., 2007. Wave run-up on cylindrical and cone shaped foundations for offshore wind turbines. Coastal Engineering. 54, 17-29.

Etemad-Shahidi, A., Bonakdar, L., 2009. Design of Rubble-Mound Breakwaters using M5' Machine Learning Method. Applied Ocean Research, 31, 197-201.

Etemad-Shahidi A, Yasa R, Kazeminezhad M. H., 2011. Prediction of wave-induced scour depth under submarine pipelines using machine learning approach. Applied Ocean Research, 33, $54-59$.

Etemad-Shahidi, A., Bali, M., 2012. Stability of Rubble-Mound Breakwaters using H50 wave height parameter. Coastal Engineering, 59, 38-45.

Etemad-Shahidi, A. and Taghipour M. ,2012. Predicting Longitudinal Dispersion Coefficient in Natural Streams Using M5' Model Tree, ASCE J. Hydraulic Engineering, 138, 542-554.

Hallermeier, R.J., 1976. Nonlinear flow of wave crests past a thin pile. J. Waterw. Harb. Coast. Eng. Div. 102 (4), 365-377.

Jafari, E., Etemad-Shahidi, A. 2012. Derivation of a new model for prediction of wave overtopping at rubble-mound structures. J. Waterw., Port, Coast., Ocean Eng., ASCE, 138 (1), 42-52.

Kazeminezhad, M.H., Etemad-Shahidi, A., 2015. A new method for the prediction of wave runup on vertical piles. Coastal Engineering. 98, 55-64. 
Kim, M.H., Hue, D.K.P., 1989. The complete second-order diffraction solution for an axisymmetric body. I: monochromatic incident waves. J. Fluid Mech. 200, 235-264.

Kriebel, D.L., 1990. Nonlinear wave diffraction by vertical circular cylinder. Part I: diffraction theory. Ocean Eng. 17, 345-377.

Lykke Andersen, T., Frigaard, P., 2006. Horns Rev II, 2-Dmodel tests. Wave run-up on pile. DCE Contract Report No. 3. Aalborg University, Denmark.

Lykke Andersen, T., Frigaard, P., Damsgaard,M., De Vos, L., 2011.Wave run-up on slender piles in design conditions-model tests and design rules for offshore wind. Coastal Engineering, $58,281-289$.

Martin, A.J., Easson,W.J., Bruce, T., 2001. Run-up on columns in steep, deep water regular waves. J. Waterw. Port Coast. Ocean Eng. 127 (1), 26-32.

Mase, H., Kosho, K., Nagahashi, S., 2001. Wave run-up of random waves on a small circular pier on sloping seabed. Journal of Waterway, Port, Coastal and Ocean Engineering 127 (4), 192 -199 .

McCamy, R., Fuchs, R., 1954. Wave forces on piles: diffraction theory. Tech. Rep. 69. Beach Erosion Board, U.S. Army Corps of Engineers.

Niedzwecki, J.M., Duggal, S.D., 1992. Wave run-up and forces on cylinders in regular and random waves. J. Waterw. Port Coast. Ocean Eng. 118, 615-634.

Niedzwecki, J.M., Huston, J.R., 1992. Wave interaction with tension leg platforms. Ocean Eng. 19 (1), 21-37.

Peng, A., Wellens, P., Raaijmakers, T., 2012. 3-D numerical modeling of wave run-up on monopiles. In proceeding of $31^{\text {st }}$ International Conference on Ocean, Offshore and Arctic Engineering (OMAE), Rio de Janeiro, Brazil.

Ramirez, J., Frigaard, P., Lykke Andersen, T., De Vos, L., 2013. Large scale model test investigation on wave run-up in irregular waves at slender piles. Coastal Engineering. 72, 69-79.

Quinlan, J. R., 1992. Learning with continuous classes. In Proceedings of AI'92 (Adams and Sterling Eds), World Scientific.343-348.

Sarpkaya, T., Isaacson, M., 1981. Mechanics of Wave Forces on Offshore Structures. Van Nostrand Reinhold Co., New York. 
Wang, Y., Witten, I.H., 1997. Induction of model trees for predicting continuous lasses. In Proceedings of the Poster Papers of the European Conference on Machine Learning, University of Economics, Faculty of Informatics and Statistics, Prague.

Yasa, R., Etemad-Shahidi, A., 2014. Classification and regression trees approach for predicting current-induced scour depth under pipelines. J. Offshore Mech. Arct. Eng. 136, 1-8. 


\section{Figure Captions}

Fig. 1: Characteristic of twin-wave flume of LWI and position of the tested pile in the flume

Fig. 2: Plan view of model set-up of LWI tests for the case of single pile

Fig. 3: Cross-section of model set-up of LWI tests for the case of single pile

Fig. 4: Side view of one wave run-up event exemplary for the test with wave height of $0.29 \mathrm{~m}$ and period of $3.5 \mathrm{sec}$

Fig. 5: Comparison of measured and predicted regular wave run-ups by De Vos et al. (2007) formula for LWI data

Fig. 6: Comparison of measured and predicted regular wave run-ups by De Vos et al. (2007) formula using those of LWI data for which second order Stokes theory is applicable

Fig. 7: Comparison of measured and predicted regular wave run-ups by Kazeminezhad and Etemad-Shahidi (2015) formulae (Eqs. 6 and 7) for LWI data

Fig. 8: Comparison of measured and predicted regular wave run-ups by Kazeminezhad and Etemad-Shahidi (2015) formula (Eq. 6) for LWI data with $H / h \leq 0.41$

Fig. 9: Example of M5 model tree (Developed tree, leaves, classified data and linear equations)

Fig. 10: Comparison of measured and predicted regular wave run-ups by new formulae (Eq. 15) for LWI data

Fig. 11: Comparison of measured and predicted regular wave run-ups by new formulae (Eq. 15) for all used data 


\section{Table captions}

Table 1. Formulae for the estimation of irregular wave run-up on single piles

Table 2: The LWI test programme for regular non-breaking waves

Table 3. Range of the LWI non-dimensional hydrodynamic parameters

Table 4. Range of the conditions used for the development of the run-up formulae

Table 5. Correlation between the non-dimensional parameters and relative wave run-up $\left(R_{u} / H\right)$

Table 6. Different $M$ factor values for various levels of acceptable risk (Yasa and Etemad-

Shahidi, 2014) 


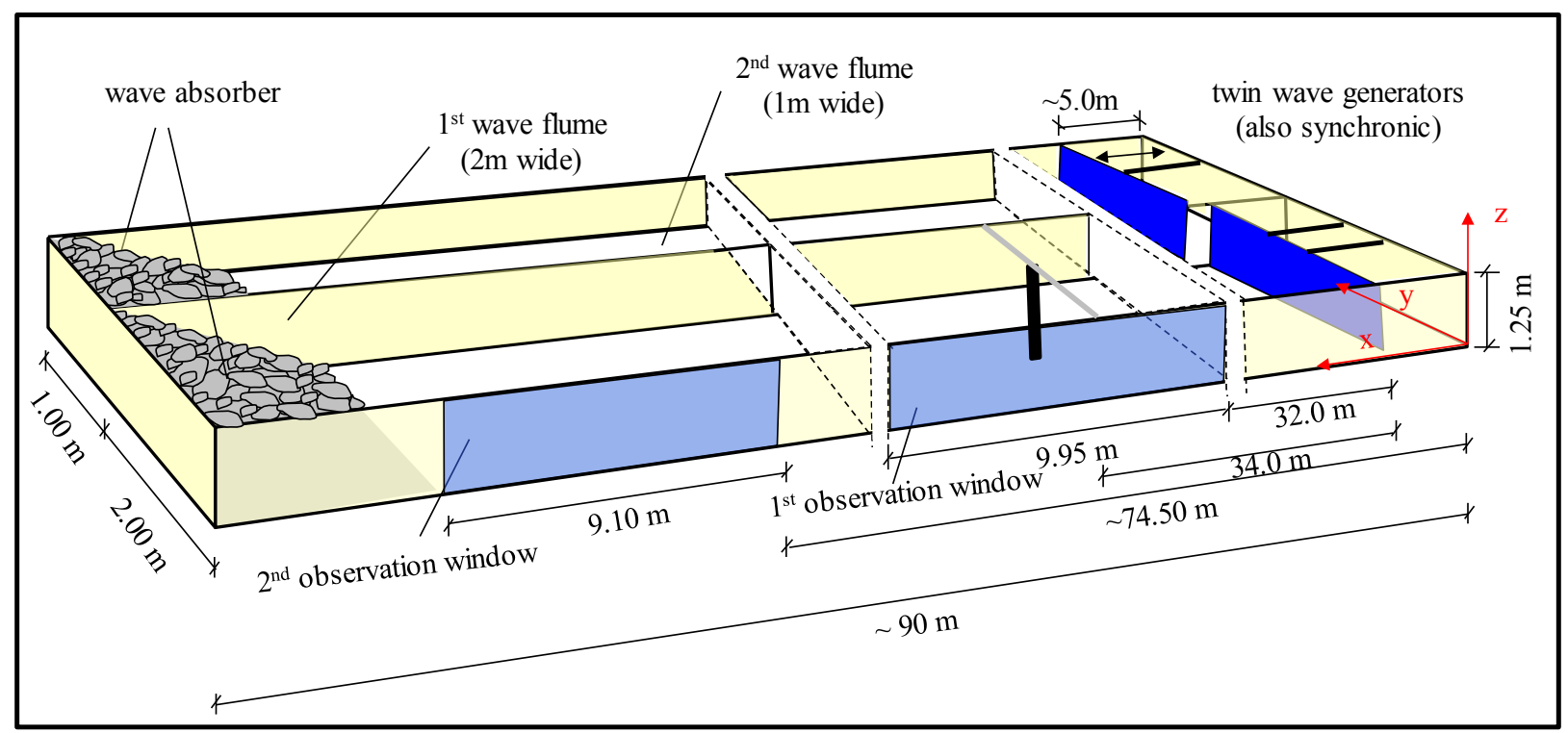

Fig. 1: Characteristic of twin-wave flume of LWI and position of the tested pile in the flume 


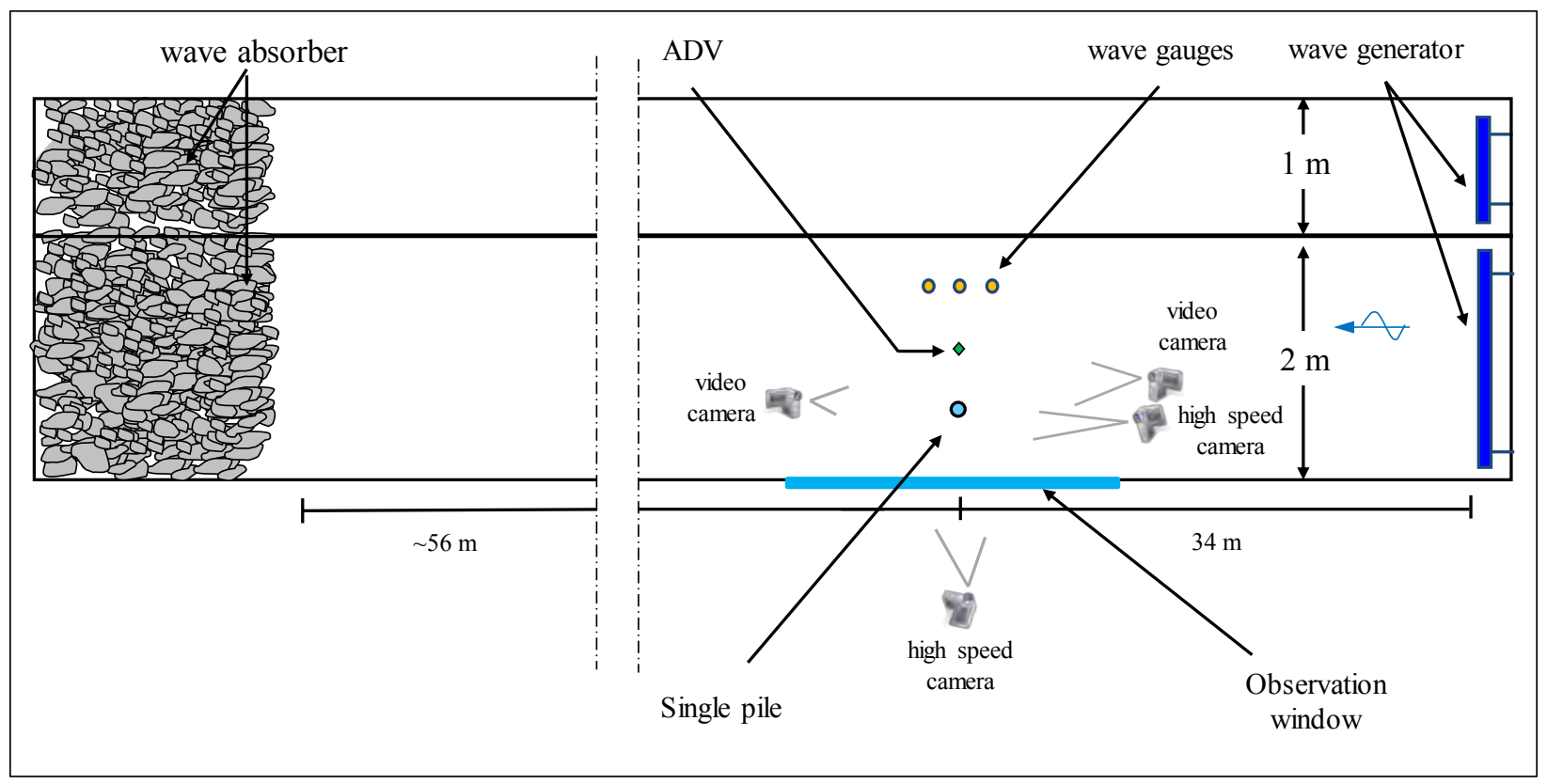

Fig. 2: Plan view of model set-up of LWI tests for the case of single pile 


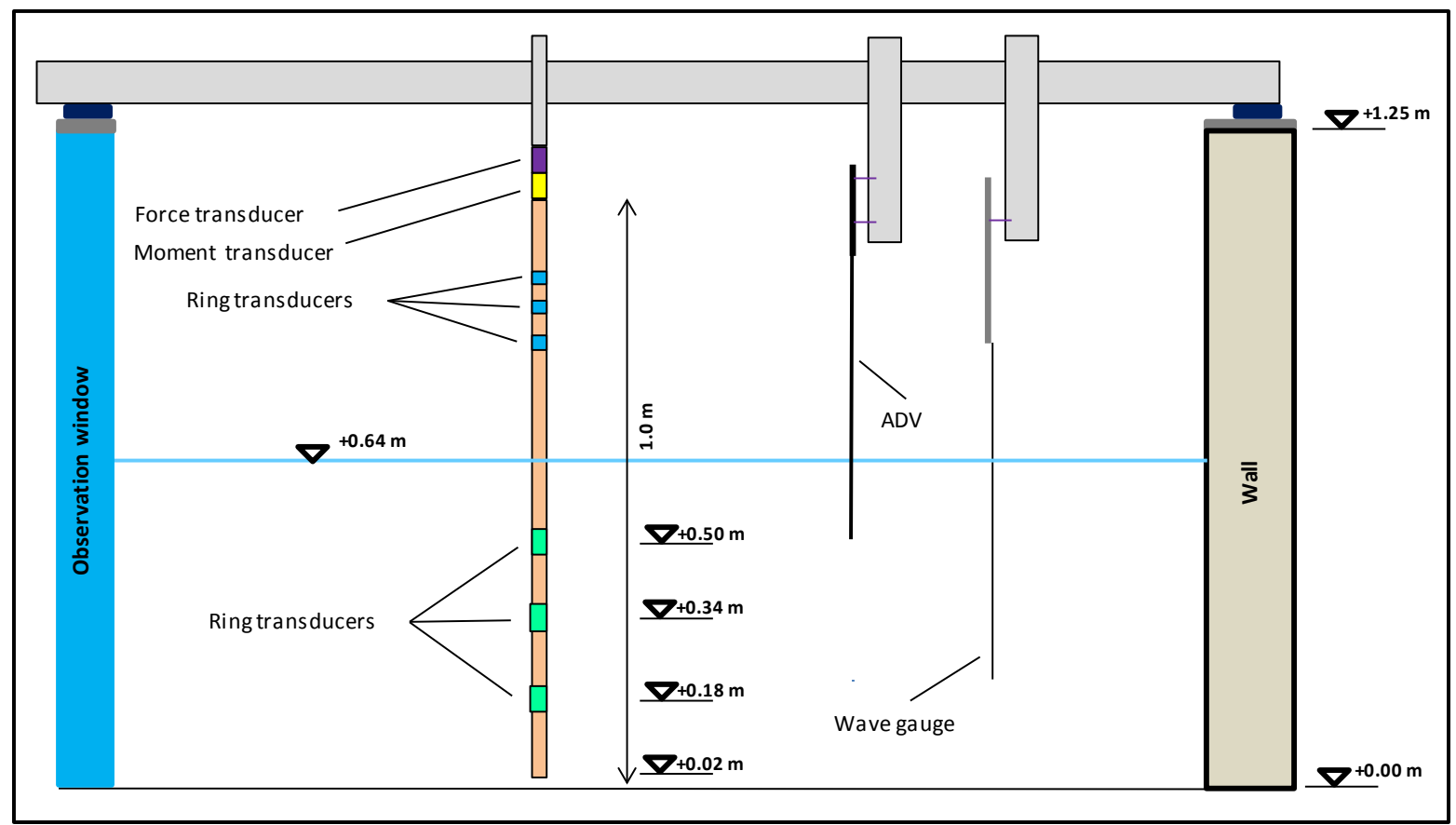

Fig. 3: Cross-section of model set-up of LWI tests for the case of single pile 

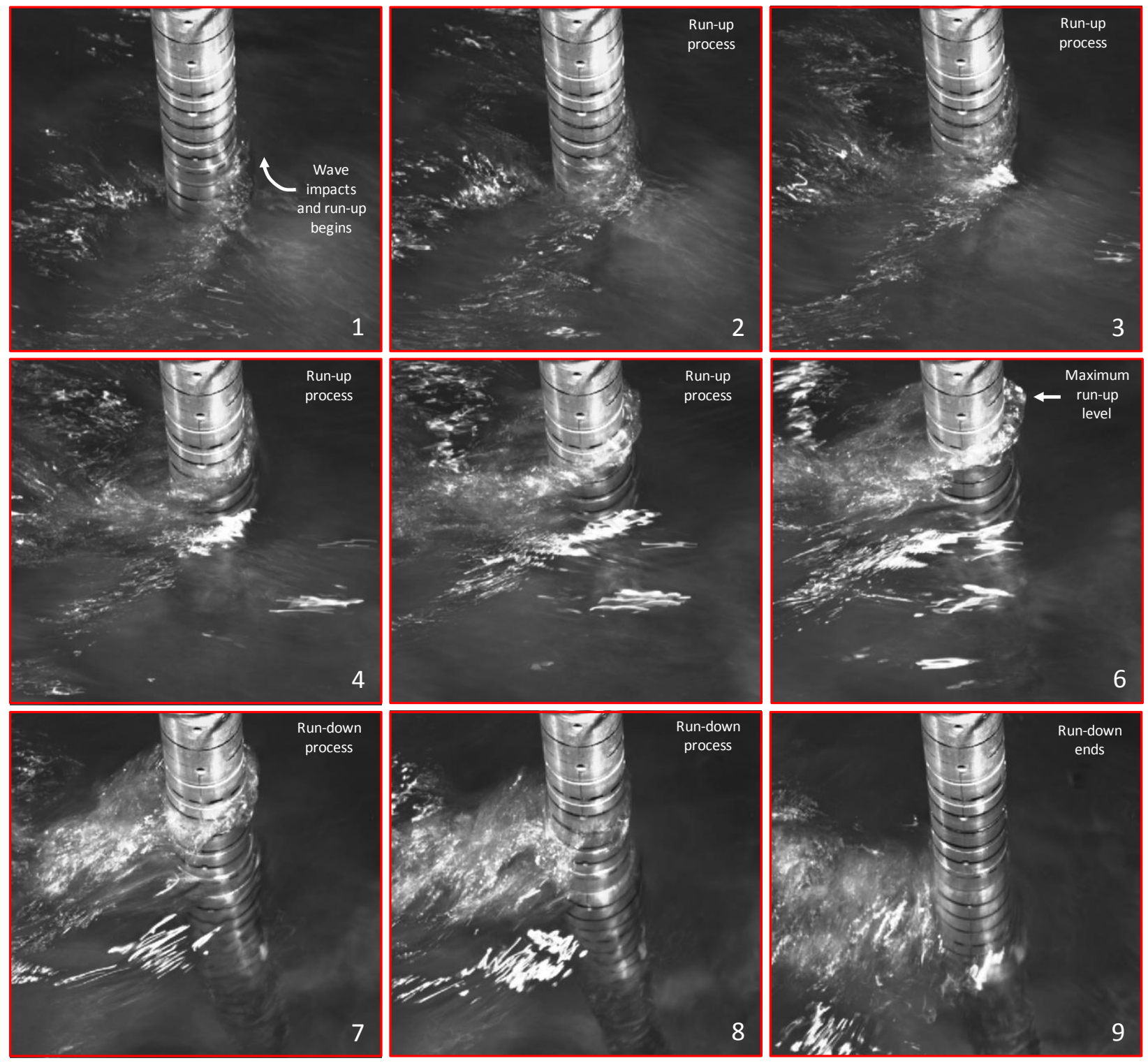

Fig. 4: Side view of one wave run-up event exemplary for the test with wave height of $0.29 \mathrm{~m}$ and period of $3.5 \mathrm{sec}$ 


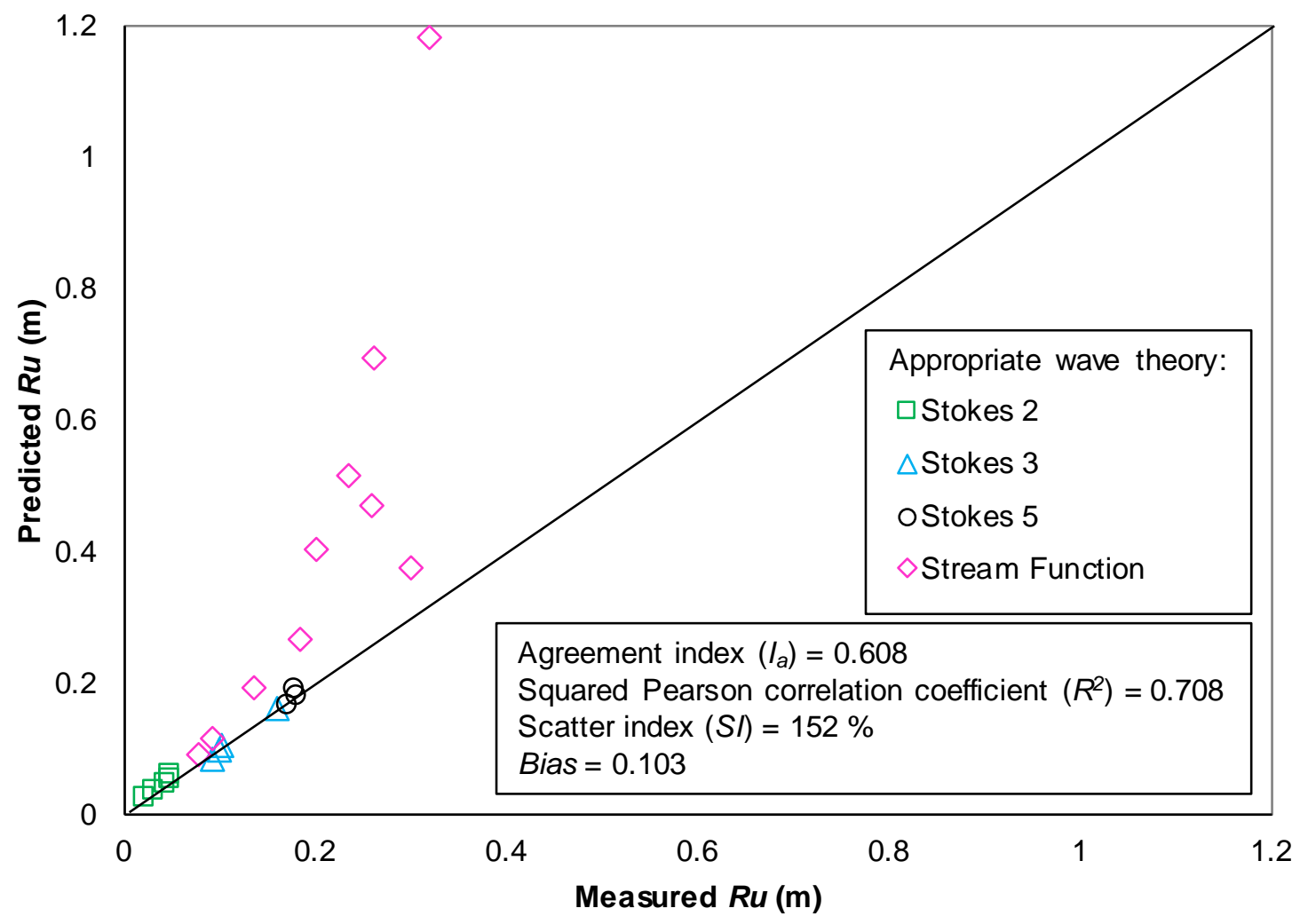

Fig. 5: Comparison of measured and predicted regular wave run-ups by De Vos et al. (2007) formula for LWI data 


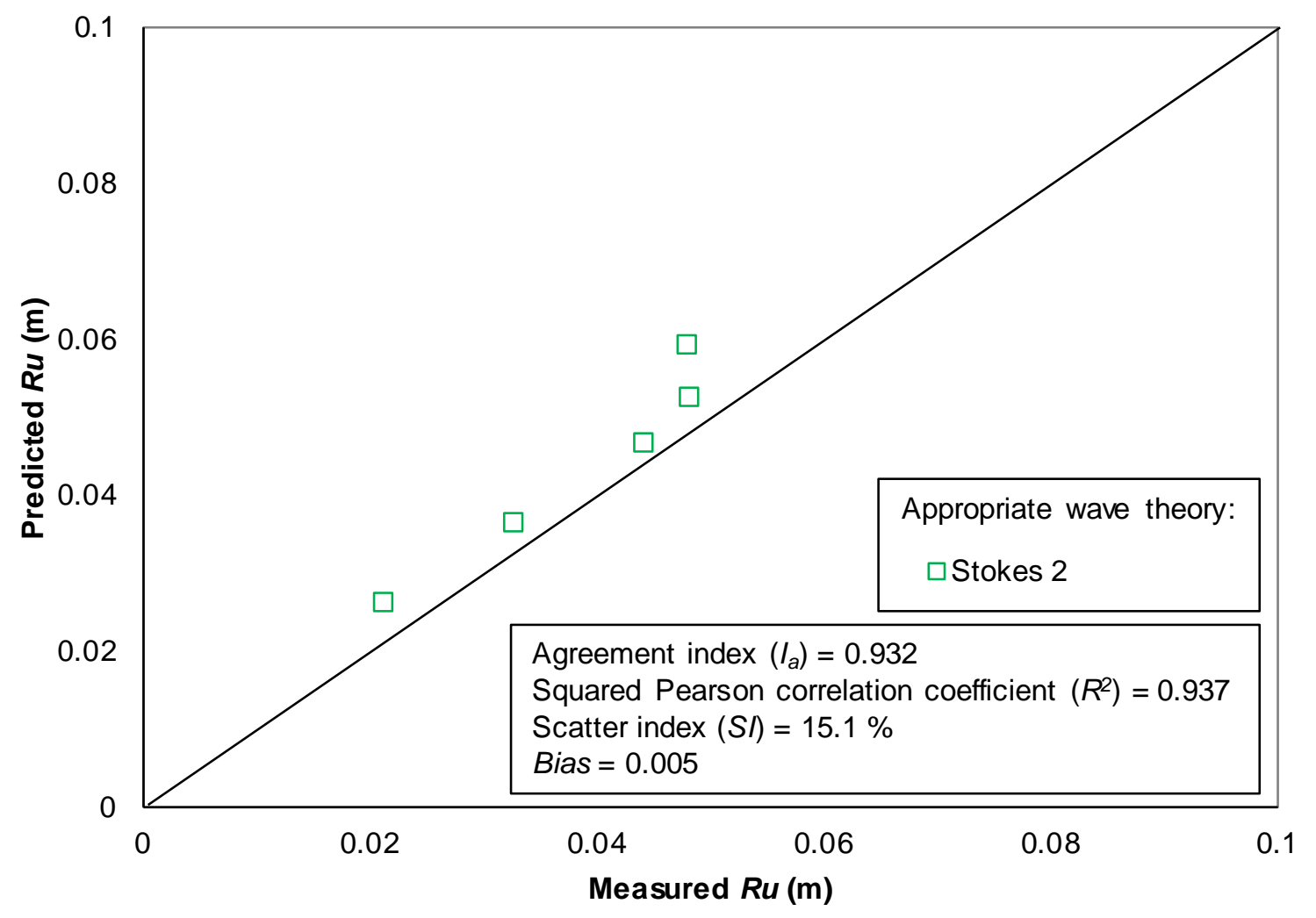

Fig. 6: Comparison of measured and predicted regular wave run-ups by De Vos et al. (2007) formula using those of LWI data for which second order Stokes theory is applicable 


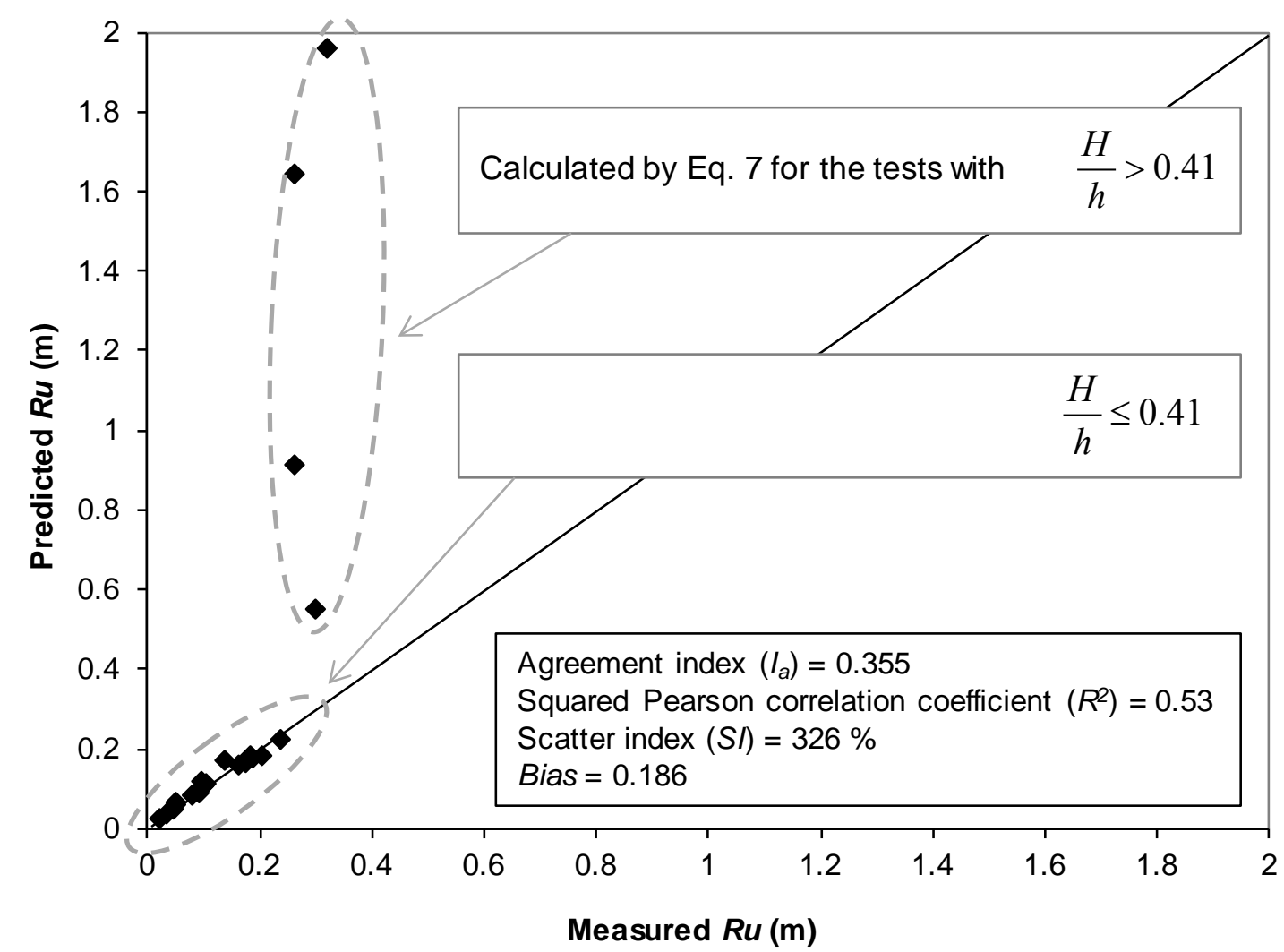

Fig. 7: Comparison of measured and predicted regular wave run-ups by Kazeminezhad and Etemad-Shahidi (2015) formulae (Eqs. 6 and 7) for LWI data 


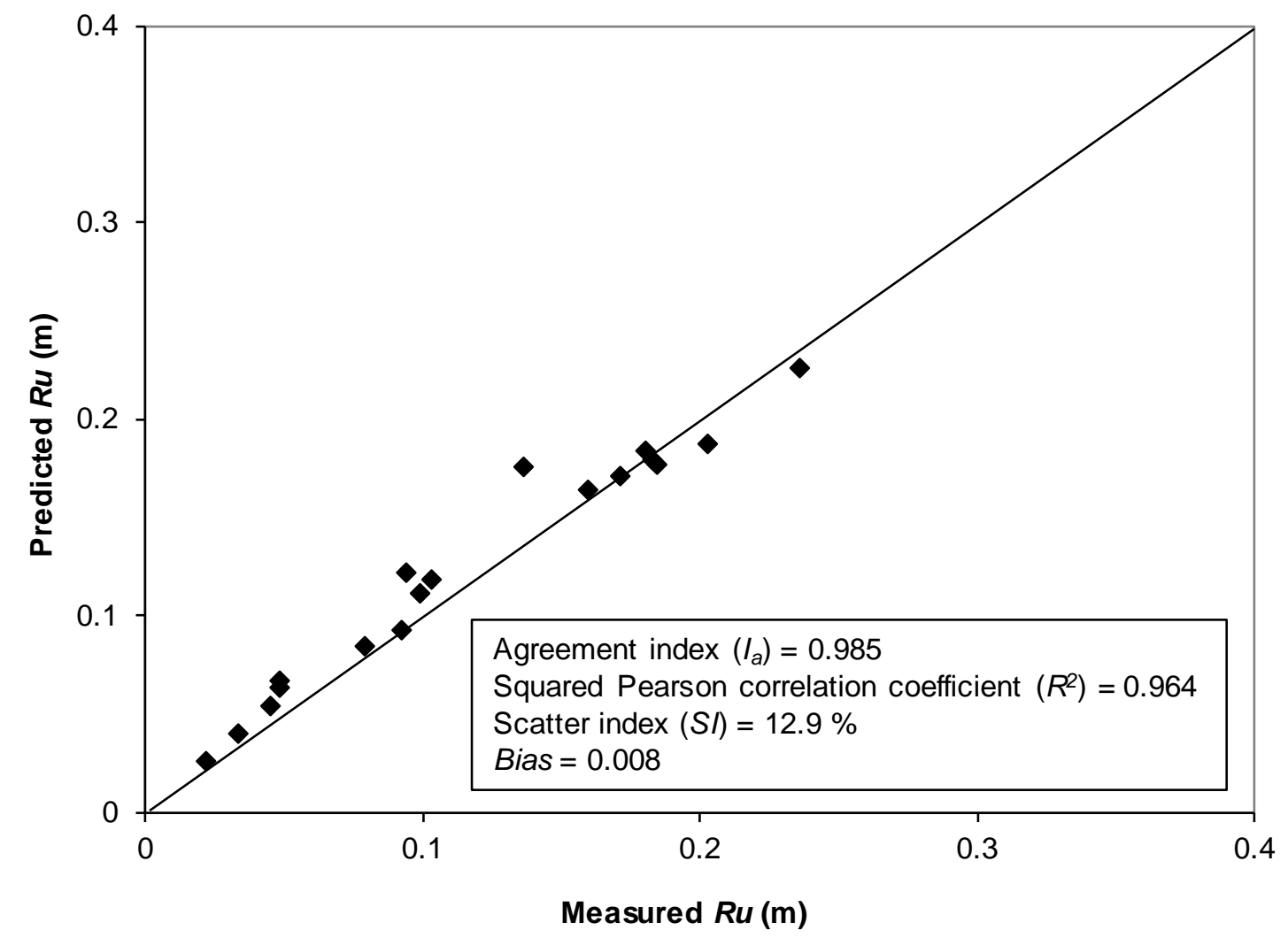

Fig. 8: Comparison of measured and predicted regular wave run-ups by Kazeminezhad and Etemad-Shahidi (2015) formula (Eq. 6) for LWI data with $H / h \leq 0.41$ 


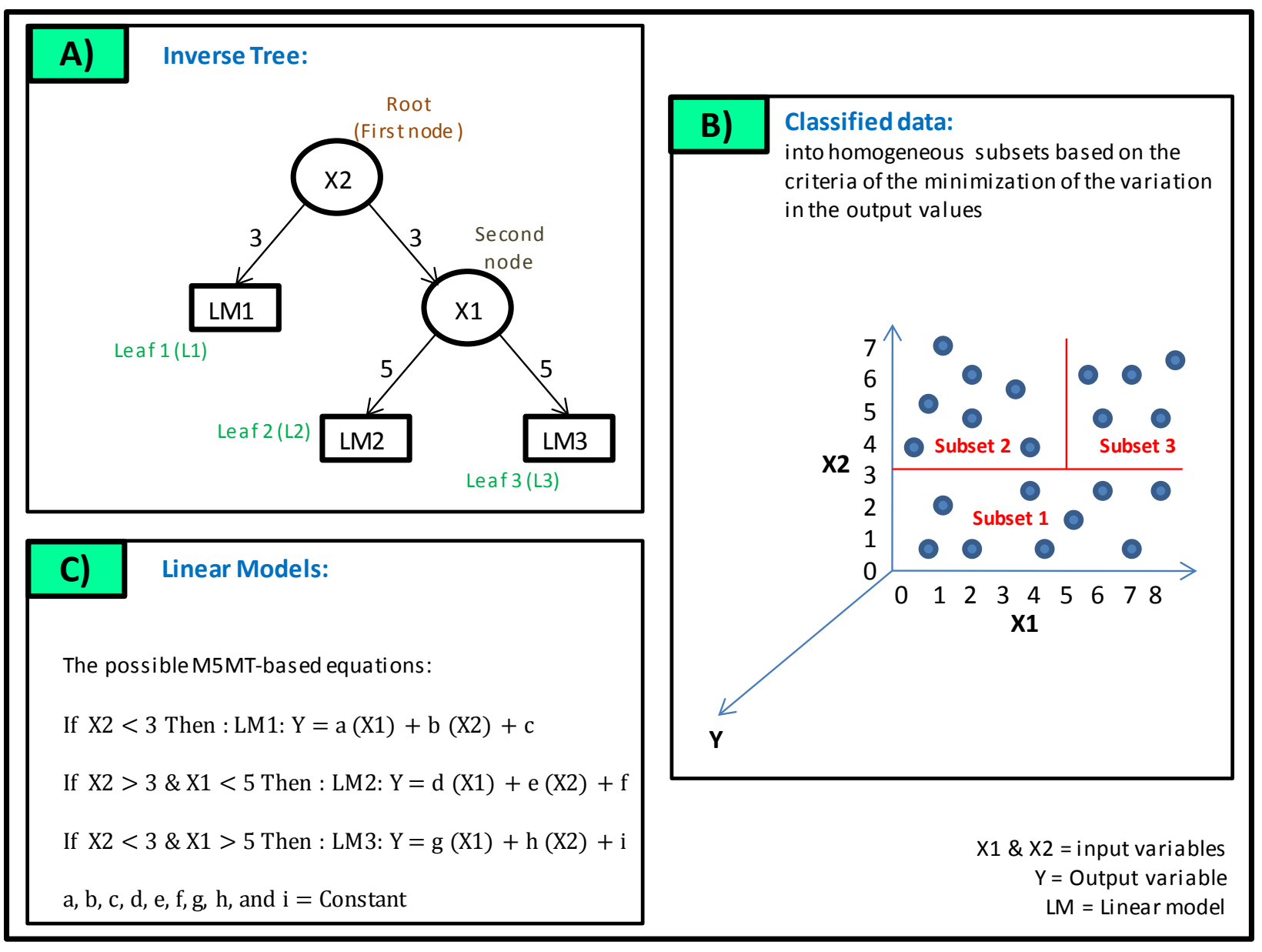

Fig. 9: Example of M5 model tree (Developed tree, leaves, classified data and linear equations) 


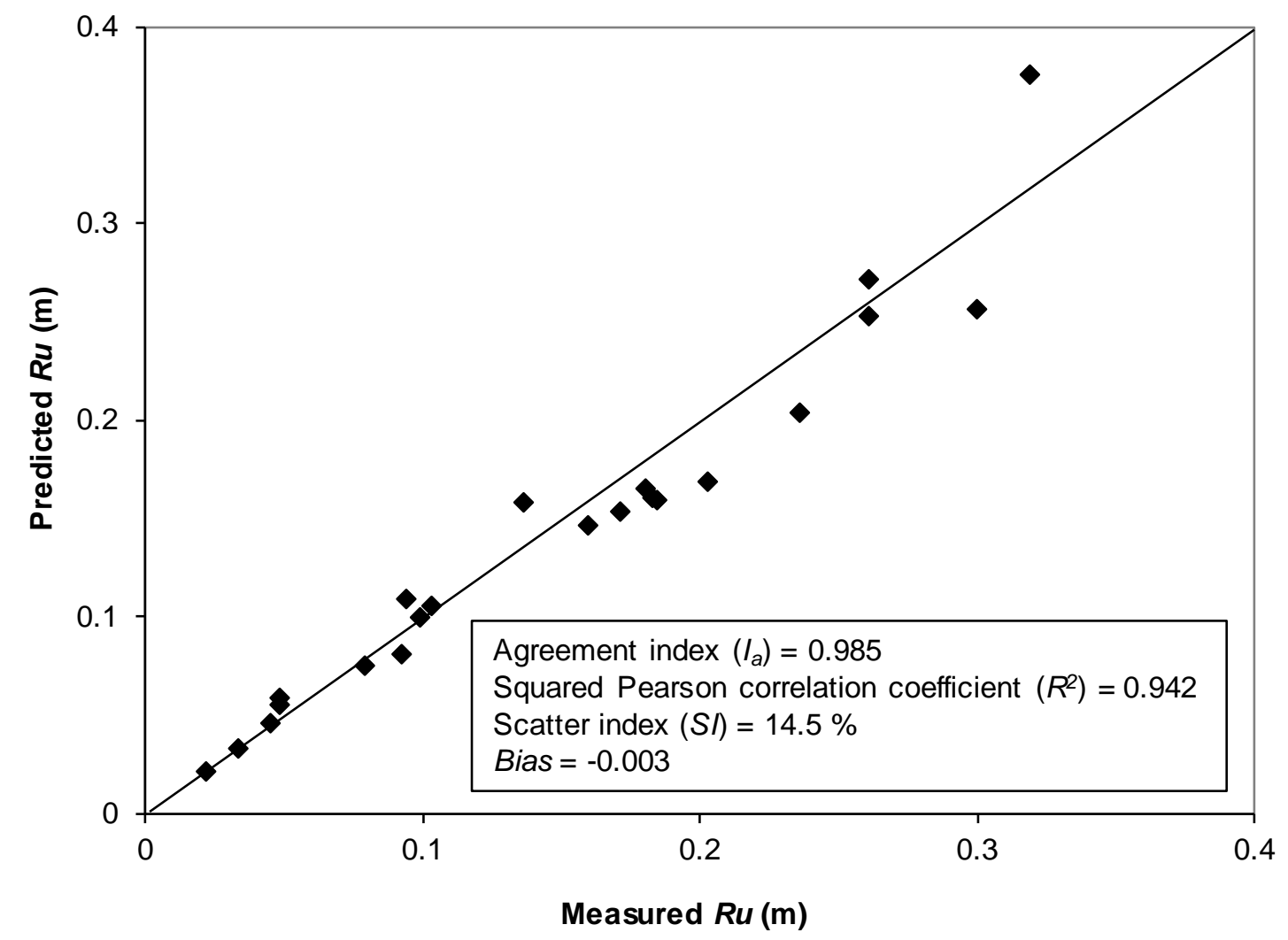

Fig. 10: Comparison of measured and predicted regular wave run-ups by new formulae (Eq. 15) for LWI data 


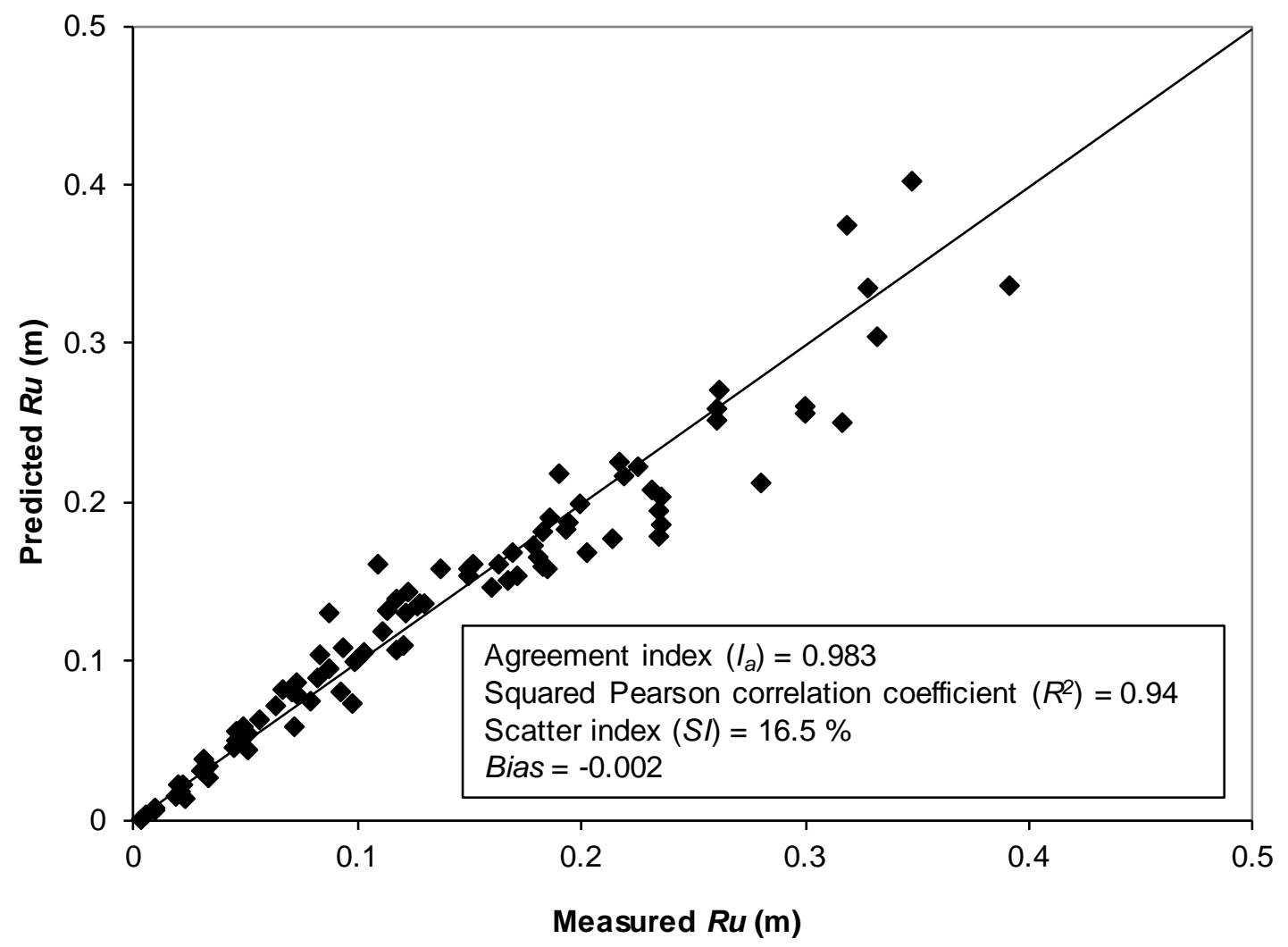

Fig. 11: Comparison of measured and predicted regular wave run-ups by new formulae (Eq. 15) for all used data 
Table 1. Formulae for the estimation of irregular wave run-up on single piles

\begin{tabular}{|c|c|}
\hline Study & Formulae \\
\hline $\begin{array}{l}\text { Mase et al. } \\
\text { (2001) }\end{array}$ & $\begin{array}{l}\frac{R_{u, 2 \%}}{h}=\left(0.24-\frac{0.004}{\tan \theta}\right)+\left(11.43-\frac{0.2}{\tan \theta}\right) \\
. \exp \left[-\left(1.55-0.77 \exp \left\{-69.46\left(\frac{H_{0}}{L_{0}}\right)\right\}\right)\left(1.02-\frac{0.015}{\tan \theta}\right)\left(\frac{h}{H_{0}}\right)\right] \\
\text { for } \quad \frac{1}{40} \leq \tan \theta \leq \frac{1}{10} \text { and } 0.004<\frac{H_{0}}{L_{0}}<0.05 \text { and } \frac{h}{H_{0}}<6\end{array}$ \\
\hline $\begin{array}{l}\text { Lykke } \\
\text { Andersen and } \\
\text { Frigaard } \\
(2006)\end{array}$ & $R_{u, 2 \%}=\eta_{\max , 2 \%}+m \frac{u_{2 \%}{ }^{2}}{2 g} \quad$ for $\quad m= \begin{cases}4 & s_{0 p}=0.02 \\
3 & s_{0 p}=0.035\end{cases}$ \\
\hline $\begin{array}{l}\text { Lykke } \\
\text { Andersen et al. } \\
\text { (2011) }\end{array}$ & $R_{u, 2 \%}=\eta_{\max , 2 \%}+m \frac{u_{2 \%}^{2}{ }^{2}}{2 g} \quad$ for $\quad m= \begin{cases}5.6 & s_{s_{p}}=0.02 \\
4.2 & s_{0 p}=0.035\end{cases}$ \\
\hline $\begin{array}{l}\text { Peng et al. } \\
\text { (2012) }\end{array}$ & $\frac{R_{u, 2 \%}}{h}=7.39 \gamma_{D} \ln (0.27 U r+1) \quad$ for $\quad \gamma_{D}=0.004 \ln \left(251.8 \frac{H}{D}+1\right)$ \\
\hline $\begin{array}{l}\text { Ramirez et al. } \\
\text { (2013) }\end{array}$ & $\begin{array}{l}R_{u, 2 \%}=\eta_{\max , 2 \%}+m \frac{u_{2 \%}^{2}}{2 g} \text { for classified wave run-up levels A, B and C } \\
\text { Level A: } m= \begin{cases}-66.667 s_{s_{p}}+5.33 & s_{0_{p}}<0.035 \\
3 & s_{0_{p}}>0.035\end{cases} \\
\text { Level B: } m= \begin{cases}-93.33 s_{0_{p}}+7.47 & s_{0_{p}}<0.035 \\
4.2 & s_{0_{p} p}>0.035\end{cases} \\
\text { Level C: } m= \begin{cases}-200 s_{0_{p}}+16 & s_{s_{p}}<0.035 \\
9 & s_{0 p}>0.035\end{cases} \end{array}$ \\
\hline $\begin{array}{l}\text { Kazeminezhad } \\
\text { and Etemad- } \\
\text { Shahidi (2015) }\end{array}$ & $\begin{array}{l}\frac{R_{u, 2 \%}}{H_{m 0}}=1.4\left(\frac{H_{m 0}}{h}\right)^{0.15}\left(\frac{H_{m 0}}{L_{0 p}}\right)^{-0.055} \text { for } \frac{H_{m 0}}{h} \leq 0.36 \\
\frac{R_{u, 2 \%}}{H_{m 0}}=1.2\left(\frac{H_{m 0}}{L_{0 p}}\right)^{-0.055}+8.5 \times 10^{-4}\left(\frac{H_{m 0}}{h}-0.36\right)^{0.15}\left(\frac{H_{m 0}}{L_{0 p}}\right)^{-1.5} \text { for } \frac{H_{m 0}}{h}>0.36\end{array}$ \\
\hline \multicolumn{2}{|c|}{$\begin{array}{l}R_{u, 2 \%} \text { is wave run-up levels exceeded by } 2 \% \text { of the waves } \\
\eta_{\text {max }}, 2 \% \text { is the crest level of the } 2 \% \text { highest wave } \\
u_{2 \%} \text { is the horizontal wave-induced flow velocity at the wave crest } \\
\theta \text { is bottom slope }\end{array}$} \\
\hline
\end{tabular}


Table 2: The LWI test programme for regular non-breaking waves

\begin{tabular}{|c|c|c|c|c|c|c|c|c|c|}
\hline $\begin{array}{l}\text { Test } \\
\text { number }\end{array}$ & $\begin{array}{l}\text { Water } \\
\text { depth } \\
\text { (m) }\end{array}$ & $\begin{array}{l}\text { Wave } \\
\text { height } \\
\text { (m) }\end{array}$ & $\begin{array}{l}\text { Wave } \\
\text { period } \\
\text { (s) }\end{array}$ & $\begin{array}{l}\text { Wave } \\
\text { water } \\
\text { depth } \\
(h / L)\end{array}$ & $\begin{array}{l}\text { Wave } \\
\text { steepness } \\
(H / L)\end{array}$ & $\begin{array}{l}\text { Pile } \\
\text { slenderness } \\
(D / L)\end{array}$ & $\begin{array}{l}\text { Relative } \\
\text { wave } \\
\text { height } \\
(H / h)\end{array}$ & $\begin{array}{l}\text { Wave run- } \\
\operatorname{up}_{(\mathrm{m})}(R)^{(*)} \\
(\mathrm{m})\end{array}$ & $\begin{array}{l}R u \text { 's } \\
\text { Relative } \\
\text { standard } \\
\text { deviation } \\
(R S D)^{(* *} \\
(\%)\end{array}$ \\
\hline 1 & 0.64 & 0.044 & 0.8 & 0.643 & 0.044 & 0.050 & 0.070 & 0.0213 & 5.45 \\
\hline 2 & 0.64 & 0.062 & 1.0 & 0.419 & 0.040 & 0.033 & 0.098 & 0.0328 & 4.11 \\
\hline 3 & 0.64 & 0.080 & 1.2 & 0.302 & 0.036 & 0.024 & 0.126 & 0.0443 & 1.61 \\
\hline 4 & 0.64 & 0.087 & 2.5 & 0.108 & 0.014 & 0.008 & 0.136 & 0.0483 & 3.17 \\
\hline 5 & 0.64 & 0.088 & 3.5 & 0.074 & 0.010 & 0.006 & 0.139 & 0.0481 & 3.46 \\
\hline 6 & 0.64 & 0.105 & 5.0 & 0.051 & 0.008 & 0.004 & 0.166 & 0.0789 & 1.49 \\
\hline 7 & 0.64 & 0.133 & 1.2 & 0.302 & 0.061 & 0.024 & 0.208 & 0.0918 & 3.91 \\
\hline 8 & 0.64 & 0.149 & 2.0 & 0.141 & 0.031 & 0.011 & 0.234 & 0.0986 & 2.51 \\
\hline 9 & 0.64 & 0.153 & 2.5 & 0.108 & 0.025 & 0.008 & 0.241 & 0.1026 & 4.87 \\
\hline 10 & 0.64 & 0.154 & 3.0 & 0.088 & 0.020 & 0.007 & 0.242 & 0.0933 & 3.56 \\
\hline 11 & 0.64 & 0.209 & 4.7 & 0.055 & 0.018 & 0.004 & 0.326 & 0.1841 & 5.95 \\
\hline 12 & 0.64 & 0.213 & 6.0 & 0.042 & 0.014 & 0.003 & 0.336 & 0.2022 & 1.12 \\
\hline 13 & 0.64 & 0.275 & 4.7 & 0.055 & 0.023 & 0.004 & 0.430 & 0.2600 & 1.30 \\
\hline 14 & 0.64 & 0.255 & 5.5 & 0.046 & 0.018 & 0.003 & 0.401 & 0.2353 & 3.46 \\
\hline 15 & 0.64 & 0.275 & 6.0 & 0.042 & 0.018 & 0.003 & 0.428 & 0.2606 & 2.48 \\
\hline 16 & 0.64 & 0.217 & 1.5 & 0.210 & 0.068 & 0.016 & 0.342 & 0.1594 & 2.62 \\
\hline 17 & 0.64 & 0.217 & 2.0 & 0.141 & 0.045 & 0.011 & 0.343 & 0.1710 & 6.18 \\
\hline 18 & 0.64 & 0.228 & 2.5 & 0.108 & 0.037 & 0.008 & 0.359 & 0.1797 & 1.37 \\
\hline 19 & 0.64 & 0.215 & 3.0 & 0.088 & 0.028 & 0.007 & 0.339 & 0.1362 & 6.25 \\
\hline 20 & 0.64 & 0.29 & 3.5 & 0.074 & 0.033 & 0.006 & 0.458 & 0.2993 & 4.42 \\
\hline 21 & 0.64 & 0.328 & 6.0 & 0.043 & 0.022 & 0.003 & 0.517 & 0.3183 & 1.07 \\
\hline 22 & 0.64 & 0.233 & 1.5 & 0.211 & 0.073 & 0.016 & 0.370 & 0.1819 & 2.87 \\
\hline
\end{tabular}

(*) Average value of the measured wave run-up events in a regular wave train $(N=5$ to 15$)$

(**) Relative standard deviation of the measured wave run-up events in a regular wave train 
Table 3. Range of the LWI non-dimensional hydrodynamic parameters

\begin{tabular}{cc}
\hline Wave type & Non-breaking regular waves \\
\hline Relative water depth $(h / L)$ & $0.042 \sim 0.640$ \\
\hline Wave steepness $(H / L)$ & $0.008 \sim 0.073$ \\
\hline Pile slenderness $(D / L)$ & $0.003 \sim 0.050$ \\
\hline Relative wave height $(H / h)$ & $0.07 \sim 0.517$ \\
\hline
\end{tabular}


Table 4. Range of the conditions used for the development of the run-up formulae

\begin{tabular}{lllll}
\hline Data set & Wave type & $\begin{array}{l}\text { Relative wave } \\
\text { height }(H / h)\end{array}$ & $\begin{array}{l}\text { Relative water } \\
\text { depth }(h / L)\end{array}$ & $\begin{array}{l}\text { Pile } \\
\text { slenderness } \\
(D / L)\end{array}$ \\
\hline $\begin{array}{l}\text { Lykke Andersen } \\
\text { and Frigaard (2006) }\end{array}$ & Non-breaking & $0.410 \sim 0.520$ & $0.085 \sim 0.140$ & $0.021 \sim 0.070$ \\
\hline $\begin{array}{l}\text { De Vos et al. } \\
(2007)\end{array}$ & Non-breaking & $0.028 \sim 0.593$ & $0.084 \sim 0.861$ & $0.020 \sim 0.206$ \\
\hline $\begin{array}{l}\text { This study (LWI } \\
\text { tests) }\end{array}$ & Non-breaking & $0.070 \sim 0.517$ & $0.042 \sim 0.640$ & $0.003 \sim 0.050$ \\
\hline All data sets & Non-breaking & $0.028 \sim 0.593$ & $0.042 \sim 0.861$ & $0.003 \sim 0.206$ \\
\hline
\end{tabular}


Table 5. Correlation between the non-dimensional parameters and relative wave run-up $\left(R_{u} / H\right)$

\begin{tabular}{cc}
\hline Non-dimensional parameter & Squared Pearson correlation coefficient $\left(R^{2}\right)$ \\
\hline Relative wave height $(H / h)$ & 0.60 \\
\hline Relative water depth $(h / L)$ & 0.16 \\
\hline Pile slenderness $(D / L)$ & 0.07 \\
\hline
\end{tabular}


Table 6. Different $M$ values for various levels of acceptable risk (Yasa and Etemad-Shahidi, 2014)

\begin{tabular}{cc}
\hline Acceptable risk (\%) & $M$ \\
\hline 2 & 2.05 \\
\hline 5 & 1.65 \\
\hline 10 & 1.28 \\
\hline 33 & 0.44 \\
\hline 50 & 0 \\
\hline
\end{tabular}

